\title{
Potencial de plantas acuáticas para la remoción de coliformes totales y Escherichia coli en aguas servidas
}

\section{(Evaluation of the potential of acuatic plants to remove total coliforms and Escherichia coli from wastewater)}

\author{
León $\mathrm{R}^{1}$, Pernía $\mathrm{B}^{1}$, Siguencia $\mathrm{R}^{1}$, Franco $\mathrm{S}^{1}$, Noboa $\mathrm{A}^{1}$, Cornejo $\mathrm{X}^{1}$
}

\begin{abstract}
Resumen:
En el Ecuador, muchas comunidades dependen del agua superficial no tratada como la principal fuente de agua potable y estas se encuentran contaminadas con coliformes fecales y Escherichia coli. El objetivo de esta investigación fue encontrar plantas acuáticas con potencial de remover $E$. coli y coliformes totales de agua contaminada. Se realizaron muestreos en: el Río Guayas, el Recinto Aguas Frías y el Estero Peñafiel donde se seleccionaron las especies: Azolla caroliniana Willd, Eichhornia crassipes (Mart.) Solms, Pistia stratiotes L., Salvinia auriculata Aubl. y Lemna minor L. Las plantas se reprodujeron in vitro y se realizaron bioensayos para verificar su capacidad de remover $E$. coli y coliformes. También se determinaron los parámetros fitoquímicos: temperatura, $\mathrm{pH}$ y sólidos totales disueltos. Los ensayos se realizaron por triplicado en agua con fertilizante y se inoculó una cepa de referencia E. coli ATCC25922. Al transcurrir siete días se determinó la carga bacteriana remanente y se obtuvo un porcentaje de remoción de $E$. coli en comparación al control del 99\% para $A$. caroliniana, E. crassipes y Lemna sp., mientras que para $P$. stratiotes y $S$. auriculata fue del $100 \%(p=0.027)$. Una vez evidenciado el potencial de estas especies para remover las bacterias, se realizaron ensayos con aguas servidas en los cuales $S$. auriculata y $A$. caroliniana lograron el $100 \%$ de remoción de las coliformes y $E$. coli ( $p$ $=0.003$ ). Se sugiere el uso de $S$. auriculata y $A$. caroliniana para el tratamiento de las aguas.
\end{abstract}

Palabras clave: fitorremediación; E. coli ATCC25922; A. caroliniana; S. auriculata

\begin{abstract}
:
In Ecuador, most communities rely on non-treated surface water as their main drinkable water source. In most cases, the water source is contaminated with fecal coliforms and Escherichia coli. This research is intended to find aquatic plants with the ability to remove the overall coliforms and E. coli from contaminated water. Aquatic plants were taken in Rio Guayas, Recinto Aguas Frias and Estero Peñafiel, and the following species were selected to carry out the experiment: Azolla caroliniana Willd, Eichhornia crassipes (Mart.) Solms, Pistia stratiotes L., Salvinia auriculata Aubl. and Lemna minor L. specimens of these plants were grown in vitro to verify their capacity and ability to remove E. coli and the coliforms using a bioassay method. Physico-chemical parameters were also tested, such as: temperature, $\mathrm{PH}$ levels and total dissolved solids. This experiment was developed in water and using a method inoculating a referential E. coli ATCC25922 strain. After 7 days the remaining bacterial percentage was determined, and it was noted a capacity of $99 \%$ of $E$. coli removal for A. caroliniana, $E$. crassipes and $L$. minor, and $100 \%$ for $P$. stratiotes and $S$. auriculata $(p=0.027)$. Once the potential of bacterial removal of these plants were proved, test were executed in wastewater, resulting in a $100 \%$ removal of coliforms and E. coli for S. auriculata and $A$. caroliniana $(\mathrm{p}=0.003)$. After the results obtained in this experiment, it is recommended to use $S$. auriculata and $A$. caroliniana as a strategy for treatment and removal of bacteria from contaminated water.
\end{abstract}

Keywords: phytoremediation; E. coli ATCC25922; A. caroliniana; S. auriculata

\footnotetext{
${ }^{1}$ Universidad de Guayaquil, Guayaquil, Ecuador (\{beatriz.pernias, rosa.siguencia, Xavier.cornejos\}
} @ug.edu.ec). 


\section{Introducción}

En el Ecuador existen comunidades que dependen del agua superficial no tratada como su fuente primaria de agua potable (Rao et al., 2015). Lamentablemente, estas fuentes superficiales son el sumidero de aguas servidas que contienen residuos humanos con una gran carga bacteriana, en especial de coliformes fecales.

La ingestión de agua contaminada representa uno de los principales causantes de enfermedades gastrointestinales en humanos y se ha descrito que en los países en desarrollo $E$. coli causa el $40 \%$ de las diarreas en niños menores de 5 años (OMS, 2015; Levy et al., 2012). Se calcula que anualmente mueren 2.5 millones de niños por diarreas a nivel mundial (OMS, 2013). En el Noreste de Ecuador la prevalencia de E. coli es de 8 personas infectadas por cada mil personas (Bhavnani et al., 2016).

En la búsqueda del origen de la contaminación por E. coli en Ecuador, algunos autores han estudiado el agua de varios ríos donde se determinaron altas concentraciones de coliformes totales y fecales. En la provincia de Esmeraldas, se ha reportado la presencia de E. coli en los ríos Onzole (1248 NMP/100 ml), Cayapas (474 NMP/100 ml) y Santiago (2420 NMP /100 ml) (Wafaa et al., 2007). De igual forma, en la provincia del Guayas, en el río Yaguachi encontraron concentraciones de E. coli de $5214 \mathrm{NMP} / 100 \mathrm{ml}$ (Valencia, 2018) y en la provincia de Pichincha, en el río Quevedo 126000 NMP/100 ml (Robinson, 2015) valores superiores a los límites máximos permisibles, lo que indica que el agua de estos ríos no es apta para consumo humano, riego agrícola ni para uso pecuario. La causa de esta contaminación es el vertido a los ríos de aguas servidas sin previo tratamiento.

El efecto de la contaminación del agua se refleja en los altos niveles de parasitosis, enfermedades diarreicas, y pérdida de la biodiversidad acuática relacionadas con la mala calidad del agua en el Ecuador (Universidad Agraria del Ecuador, 2009). Según la Dirección Nacional de Vigilancia Epidemiológica del Ministerio de Salud Pública de Ecuador, en el año 2016 en la provincia de Guayas, por cada 100000 habitantes se presentaron los siguientes casos de infecciones gastrointestinales: 3033 casos de enfermedades diarreicas, 1206 de Shigelosis, 90 de Síndrome Diarreico Agudo con deshidratación y 9 de Salmonelosis (Dirección Nacional de Vigilancia Epidemiológica, 2017).

Dentro de los tratamientos que se han propuesto para saneamiento de las aguas residuales se encuentran la cloración, el tratamiento de lagunaje facultativo y la fotocatálisis heterogénea. La eficiencia de remoción de coliformes de los tratamientos tradiciones se encuentran en rangos de 55,6\% con cloración, $90 \%$ con tratamiento de lagunaje facultativo y $100 \%$ utilizando fotocatálisis heterogénea con $\mathrm{TiO}_{2}$ (Rojas-Higuera et al., 2010). Sin embargo, estos tratamientos son costosos y poco asequibles para la población rural. Actualmente se están probando nuevas técnicas que son más económicas y amigables con el ambiente. Una de estas técnicas es la fitorremediación, en la cual se utilizan plantas para remover, detoxificar y contener contaminantes orgánicos e inorgánicos del agua (Castrillo et al., 2012; Gerhardt et al., 2017; Wang et al., 2017). En estudios previos se observó que los coliformes fecales pueden ser removidos en un 99\% por las especies $E$. crassipes (Vizcaino et al., 2016), L. minor (Valderrama et al., 1987) y Phragmites australis (Mantovi, 2003).

Varios mecanismos físicos, químicos y biológicos para la remoción de coliformes fecales y bacterias patógenas en sistemas de fitorremediación han sido descritos (Wu et al., 2016). Entre los mecanismos físicos se encuentran la filtración mecánica, sedimentación y la adsorción a materia orgánica. Dentro de los biológicos la muerte natural (Green et al., 1997) y la retención en biopelículas (Brix, 1997) y los mecanismos químicos incluyen oxidación y exposición de biocidas excretados por las plantas (Axelrood et al., 1996).

Las especies más utilizadas para la fitorremediación de aguas contaminadas son plantas acuáticas ya que poseen la habilidad de absorber, eliminar o neutralizar compuestos inorgánicos y orgánicos (Delgadillo y González, 2011). En Ecuador se desconoce la capacidad de las plantas acuáticas para remover coliformes fecales y $E$. coli 
y por ello, el objetivo del presente trabajo fue determinar el potencial de plantas acuáticas para remover coliformes totales y $E$. coli en aguas servidas.

\section{Metodología}

\section{Áreas de Estudio}

Se recolectaron las especies Eichhornia crassipes (Mart.) Solms, Azolla caroliniana Willd y Pistia stratiotes L. en el río Guayas, provincia de Guayas, Ecuador (Figura 1). El helecho acuático Salvinia auriculata Aubl. y la planta Spirodela intermedia W. D. J. Koch se colectaron en el estero Peñafiel, recinto Jauneche, provincia de Los Ríos. En el recinto Aguas Frías, provincia de Los Ríos se obtuvo Lemna minor L. y Ceratopteris thalictroides (L.) Brongn fue adquirida en Acuario Kattu, Alborada, provincia de Guayas, Ecuador.

La especie Lemna minor se ha descrito como una planta acuática capaz de remover 98-99\% de coliformes totales en aguas servidas (Valderrama et al., 1987) y por ese motivo se seleccionó como control positivo.

\section{Muestras de aguas servidas}

Se establecieron 4 puntos de muestreo a lo largo de la zanja de aguas servidas ubicada dentro del Campus Mapasingue de la Universidad de Guayaquil, provincia de Guayas. Para ello se realizó un transecto donde se tomaron cuatro muestras a $30 \mathrm{~m}$ de distancia entre ellas, para un total de 4 muestras (Figura 2).

Para colecta de las muestras de aguas servidas se utilizaron recipientes estériles de $20 \mathrm{~L}$ de capacidad y se sumergieron en el centro de la zanja, luego fueron secados y desinfectado su exterior con alcohol al $70 \%$, posteriormente las aguas de los envases fueron vaciadas en un contenedor con la finalidad de homogenizar la muestra, por un lapso de $4 \mathrm{~h}$ previo a su uso para el ensayo.

\section{Reproducción de las plantas}

Las especies colectadas en el campo se reprodujeron bajo condiciones naturales. Para ello, las plantas se colocaron en envases de plástico transparentes con $3 \mathrm{~L}$ de agua y fertilizante Multiflor ${ }^{\circledR}$ según las indicaciones del fabricante a $25^{\circ}-30^{\circ} \mathrm{C}$ y luz natural (2000 lux).

\section{Reproducción de E. coli ATCC 25922}

Se reactivó la cepa E. coli ATCC 25922 en $5 \mathrm{ml}$ de agua de Peptona (Merck), posteriormente se sembró $200 \mu \mathrm{l}$ en una placa de agar Chromocult (Merck) a temperatura de $35-37^{\circ} \mathrm{C}$ durante $18-24 \mathrm{~h}$. Se tomaron $2-3$ colonias para realizar un inóculo bacteriano en $5 \mathrm{ml}$ de solución salina $0.9 \%$ y de él se adicionó $1 \mathrm{ml} \mathrm{a} 30 \mathrm{ml}$ de agua de peptona por un lapso de 18-24 h.

\section{Reproducción de coliformes totales}

Los coliformes totales se aislaron de las muestras de aguas servidas. Se tomó $1 \mathrm{ml}$ del agua servida y se sembró en medio agar Chromocult (Merck) a temperatura de $35-37^{\circ} \mathrm{C}$ durante 18-24 h y se verificó que no hubiese E. coli. Posteriormente, se aislaron en agar Chromocult y luego se purificaron en agar TSA (Merck). 
134

\section{Capacidad de las plantas para remover E. coli ATCC 25922 y coliformes totales}

Las plantas se aclimataron durante 7 días previos al bioensayo. Al momento del ensayo las macrófitas se lavaron con agua corriente, destilada y se colocaron $4 \mathrm{~g}$ en envases de plástico. Posteriormente, se realizaron los ensayos en vasos de precipitación de $500 \mathrm{ml}$ por triplicado a las cuales se inoculó una cepa de referencia E. coli ATCC25922 y coliformes totales con una concentración que se determinó previamente en cada ensayo y con un tiempo de retención de 7 días, después de ese lapso se determinó la carga bacteriana remanente. Estos ensayos se realizaron a $25^{\circ} \mathrm{C}$ y luz artificial fluorescente de 800 lux con un fotoperíodo de 12 horas.

El control negativo empleado estaba formado por la bacteria $E$. coli y coliformes Totales en agua destilada sin plantas y un control positivo con L. minor. A los 0 y 7 días de retención se determinó la concentración de $E$. coli y coliformes totales y los porcentajes de remoción según la metodología descrita en el apartado de parámetros bacteriológicos, así como los parámetros fisicoquímicos temperatura, $\mathrm{pH}$ y sólidos suspendidos según las técnicas estandarizadas (APHA/AWWA/WEF, 2012).

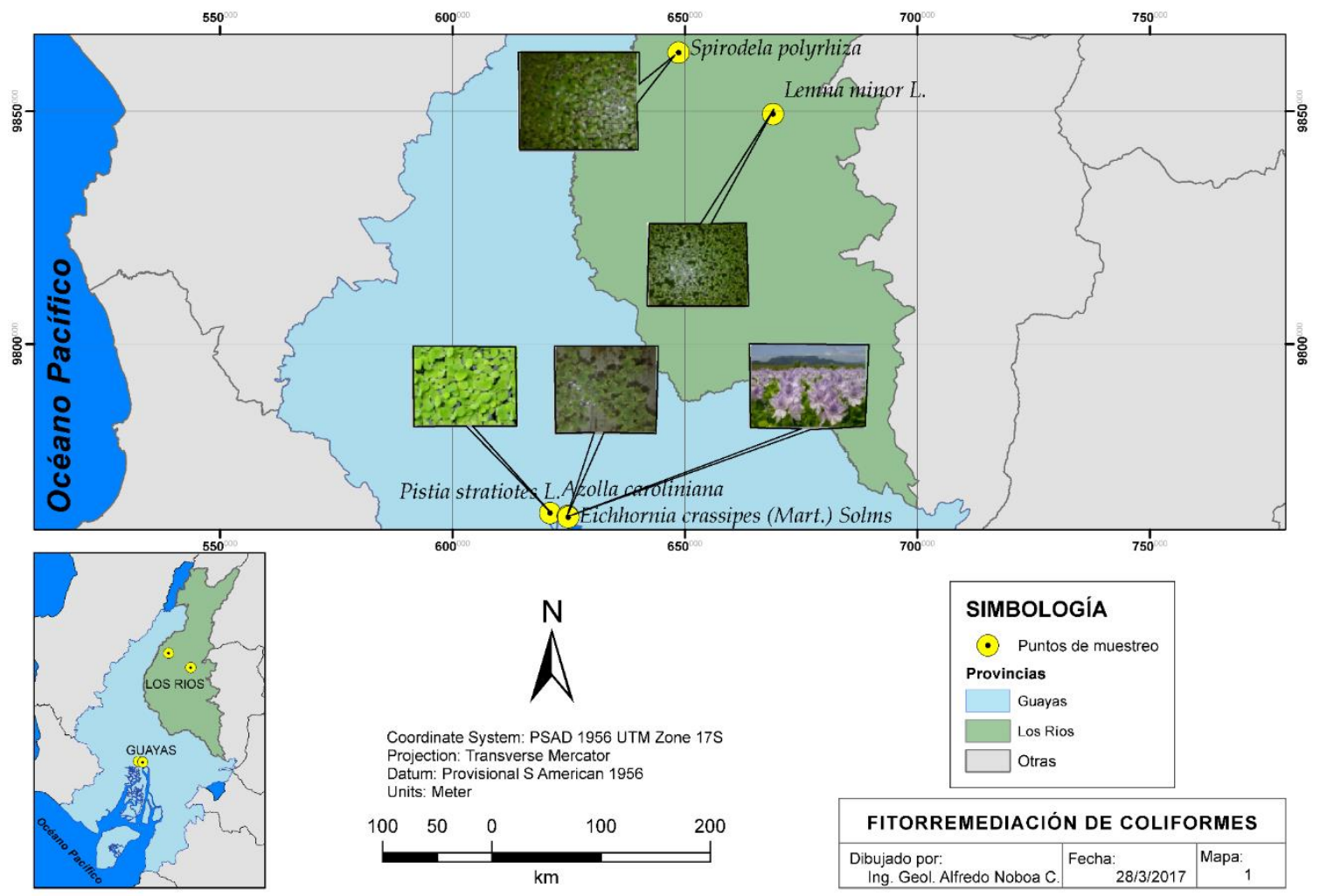

Figura 1. Área de estudio donde se muestran los sitios de colecta de las plantas acuáticas.

\section{Capacidad de las plantas para remover E. coli y coliformes totales de aguas servidas}

Una vez obtenida el agua servida, se determinó la presencia de coliformes totales y E. coli utilizando el medio de cultivo Agar Chromocult (Merck®) según la técnica EPA1.10426. El ensayo se desarrolló en recipientes con capacidad de $1000 \mathrm{ml}$ y se utilizaron $500 \mathrm{ml}$ de aguas servidas en cada envase con un tiempo de retención de 7 días. Para determinar la concentración de las bacterias se realizó un cultivo con la técnica de vertido en placa para contaje de unidades formadoras de colonias (UFC). A los 7 días de retención se determinó la concentración de $E$. coli y coliformes totales y los porcentajes de remoción según la metodología descrita en el apartado de parámetros bacteriológicos, así 
como los parámetros fisicoquímicos temperatura, $\mathrm{pH}$ y sólidos totales disueltos (TSD) según las técnicas estandarizadas (APHA/AWWA/WEF, 2012).

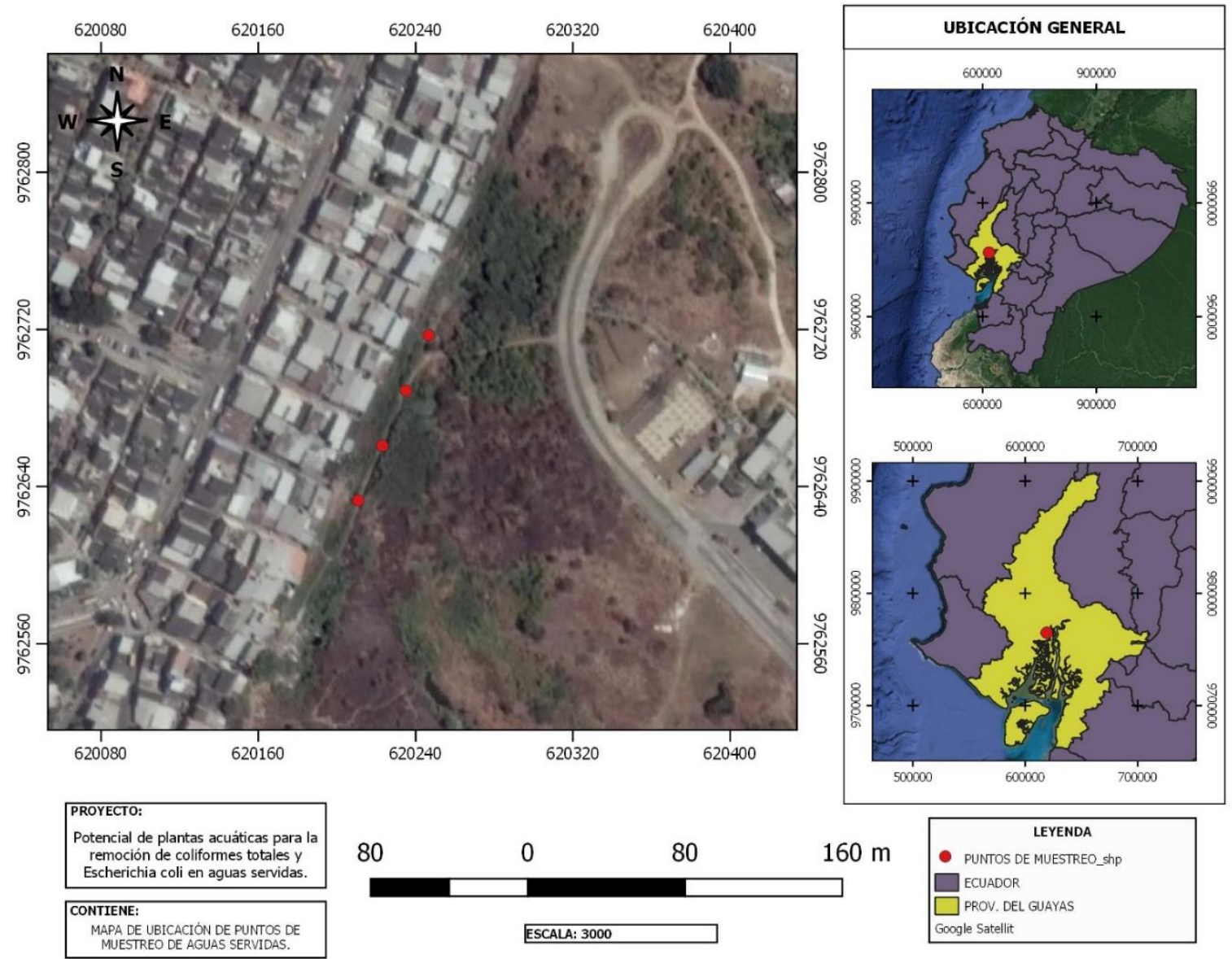

Figura 2. Mapa de ubicación de puntos de muestreo de aguas servidas.

\section{Parámetros bacteriológicos}

Para los análisis se utilizó el medio de cultivo selectivo agar Chromocult, aprobado por la EPA y la AOAC para la detección simultánea de coliformes totales y $E$. coli en muestras de agua. Se utilizó el método vertido en placa, tanto para las muestras inoculadas con E. coli y las muestras de aguas servidas. Se tomó $1 \mathrm{ml}$ de la muestra de agua proveniente de cada ensayo a las cuales se realizó diluciones sucesivas de $10^{-1}, 10^{-2}, 10^{-3}$, $10^{-4}$ y $10^{-5}$ en medio peptona, se tomó $1 \mathrm{ml}$ de cada dilución y se sembró en cajas Petri, luego se agregaron $18 \mathrm{ml}$ de agar Chromocult, se homegenizó y dejó solidificar por $10 \mathrm{~min}$. Posteriormente, se incubaron las placas a $37^{\circ} \mathrm{C}$ por $24 \mathrm{~h}$ y se procedió a contar las unidades formadoras de colonia. Para confirmar la presencia de E. coli se les agregó una gota de reactivo de Indol Kovacs, el mismo que dio una reacción positiva por el cambio de color rojo cereza después de unos segundos. Adicionalmente, se realizaron pruebas de tinción de Gram (Gram, 1884), oxidasa y motilidad (Montoya, 2008).

\section{Análisis Estadísticos}

Todos los resultados se muestran como promedio \pm desviación estándar de $n=3$ muestras. Los gráficos se realizaron utilizando el programa Origin Pro 8.

Para realizar la comparación entre tratamientos se utilizó la prueba de normalidad de Anderson-Darling y un test de igualdad de varianza de Levene. Para las muestras con distribución normal se aplicó una prueba de Anova de una vía con test a posteriori de Tukey 
$(p<0.05)$. Para las muestras que no presentaron distribución normal se aplicó una prueba no paramétrica de Kruskall-Wallis.

Finalmente, para verificar la relación entre los parámetros fisicoquímicos y la remoción de coliformes totales y $E$. coli se realizó un análisis de correlación de Spearman Rho. Para realizar todas las pruebas se utilizó el programa Minitab versión 17.

\section{Resultados}

\section{Plantas seleccionadas}

Las plantas seleccionadas fueron Spirodela intermedia W. D. J. Koch, Salvinia auriculata Aubl., Pistia stratiotes L., Eichhornia crassipes (Mart.) Solms, Ceratopteris thalictroides (L.) Brongn., Azolla caroliniana Willd y Lemna minor L. como control positivo.

\section{Capacidad de las plantas para remover E. coli ATCC 25922 y coliformes totales}

Una vez que las plantas fueron reproducidas se realizaron ensayos de laboratorio para verificar su capacidad de eliminar E. coli ATCC 25922 y coliformes fecales. Las especies $S$. intermedia, $S$. auriculata, $P$. stratiotes, $E$. crassipes y $C$. thalictroides, eliminaron en un $100 \%$ a las E. coli (Figura 3). Además, A. caroliniana, y L. minor redujeron en un $99 \%$ la población de $E$. coli en comparación al control $1.5 \times 10^{9} / 100 \mathrm{~mL}$ UFC. $A$. caroliniana redujo significativamente la concentración de $1.05 \times 10^{3} / 100 \mathrm{ml}$ UFC a $7.07 \times 10^{1 / 100} \mathrm{ml}$ UFC de $E$. coli y L. minor de $1.8 \times 10^{3} / 100 \mathrm{ml} \mathrm{UFC} \mathrm{a} 8 \times 10^{2} / 100 \mathrm{ml}$ UFC $(\mathrm{H}$ $=7.20 ; p=0.027$ ).

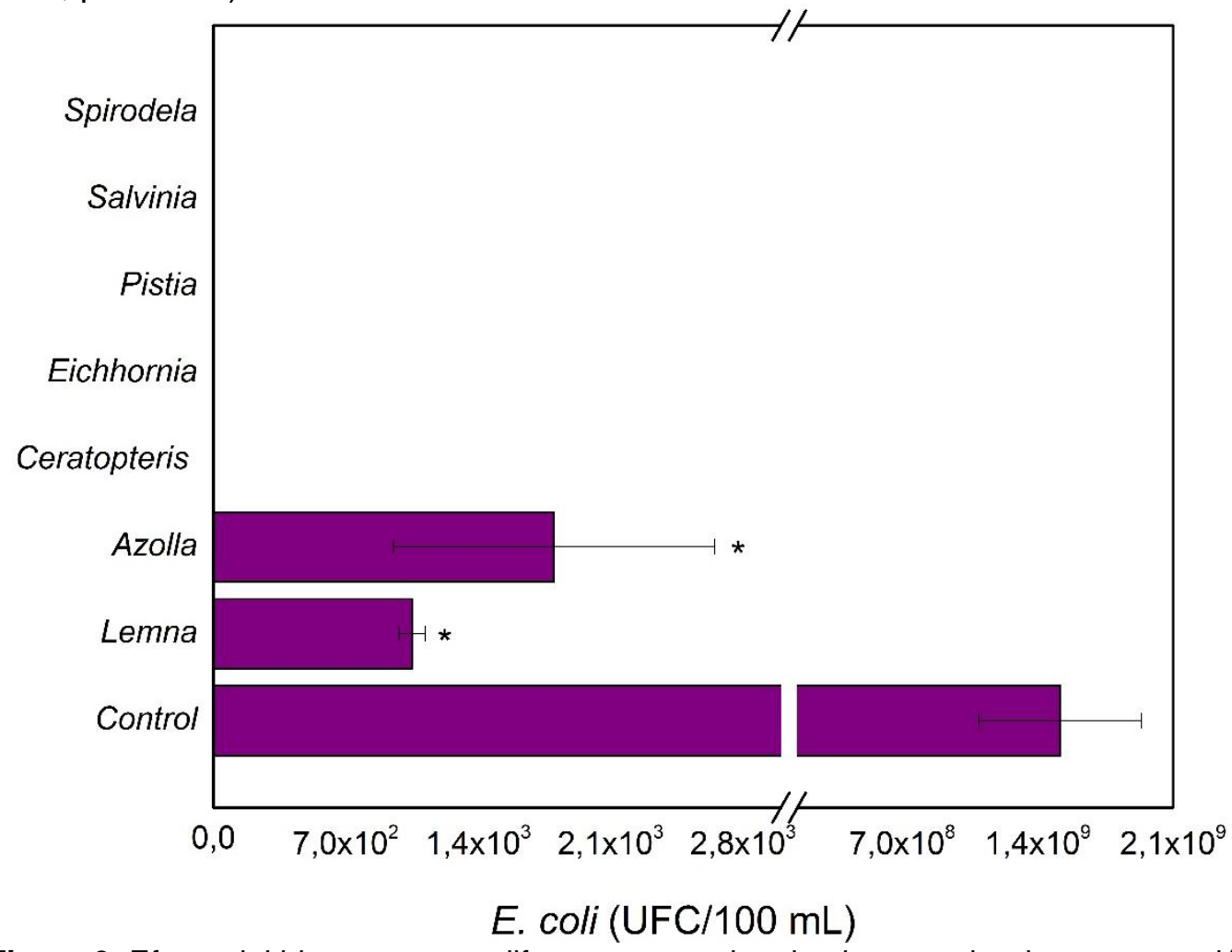

Figura 3. Efecto del bioensayo con diferentes especies de plantas sobre la concentración de $E$. coli. Los resultados se muestran como medias \pm desviación estándar. * Indica que existen diferencias significativas en comparación con el control según Kruskall-Wallis $(p<0,05)$.

En cuanto a los coliformes totales (Figura 4), se encontró que E. crassipes obtuvo la menor tasa de eliminación de coliformes totales en comparación a las otras especies vegetales que eliminaron en un $100 \%$ al agente bacteriano, pero hubo una reducción 
significativa de $7933 \mathrm{UFC} / 100 \mathrm{ml}$ en comparación al blanco $1.29 \times 10^{7} \mathrm{UFC} / 100 \mathrm{ml}(\mathrm{F}=$ 41.58; $p=0.003$.

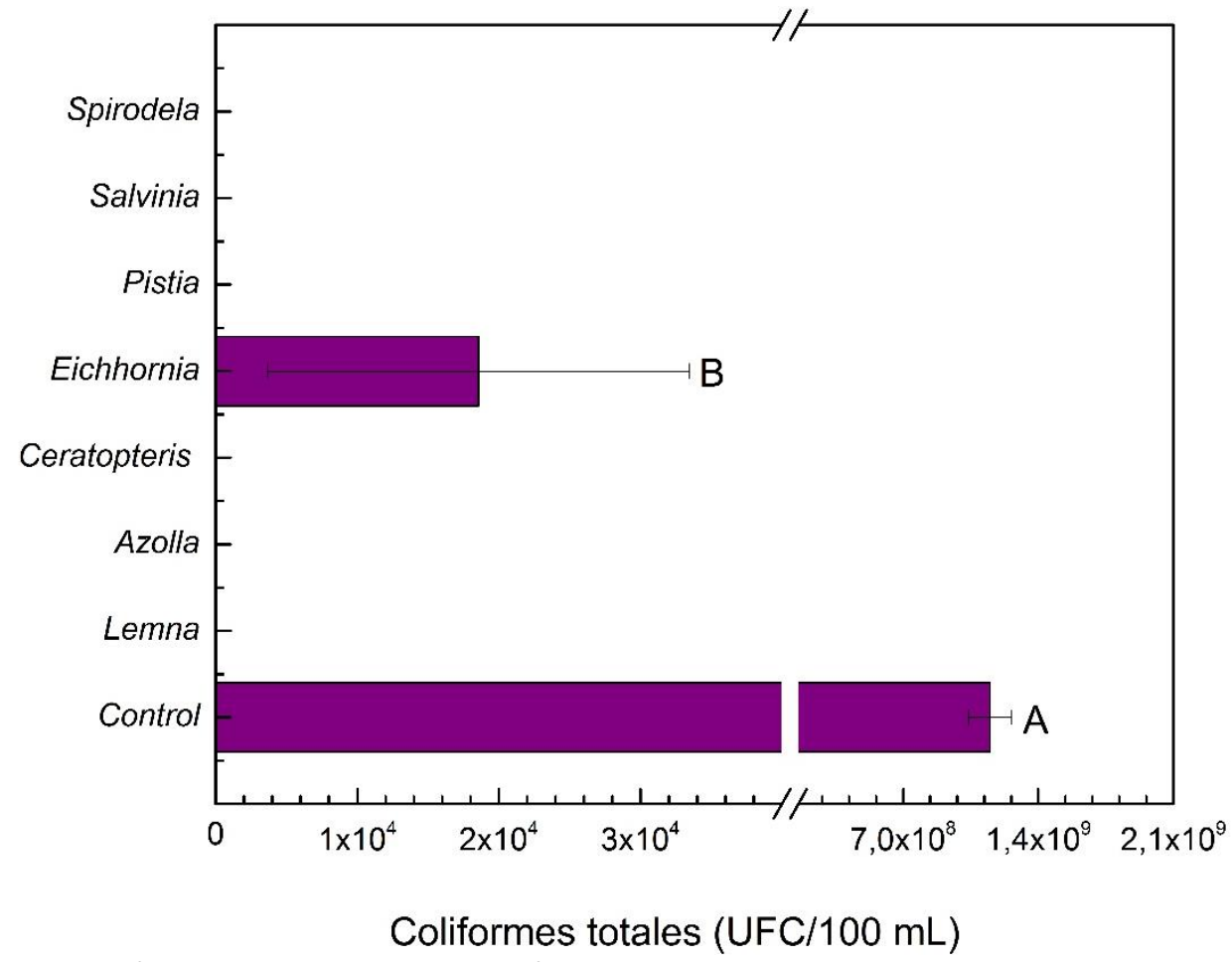

Figura 4. Efecto del bioensayo con diferentes especies de plantas sobre la concentración de coliformes totales. Los resultados se muestran como medias \pm desviación estándar. ${ }^{*}$ Indica que existen diferencias significativas en comparación con el control según Anova de una vía y test a posteriori de Tukey $(p<0,05)$.

\section{Efectos sobre los parámetros fisicoquímicos}

En el parámetro de sólidos totales disueltos (TSD), no se apreciaron diferencias significativas para la mayoría de las plantas (Tabla 1). C. thalictroides generó los niveles más altos de sólidos disueltos inclusive mayores a los del blanco, pero sus diferencias no son significativas según Kruskall-Wallis $(\mathrm{p}<0.05)$. En contraposición la $E$. crassipes presentó los niveles más bajos de TSD de $62 \mathrm{mg} / \mathrm{L}(\mathrm{F}=6.82 ; \mathrm{p}=0.001)$.

Tabla 1. Efecto del bioensayo con diferentes especies de plantas sobre el $\mathrm{pH}$, temperatura $\left(\mathrm{T}^{\circ} \mathrm{C}\right)$ y sólidos totales disueltos (TSD). Los resultados se muestran como medias \pm desviación estándar.

\begin{tabular}{|l|c|c|c|c|c|c|}
\hline \multirow{2}{*}{ Especie } & \multicolumn{2}{|c|}{ pH } & \multicolumn{2}{c|}{ T ( $\left.{ }^{\circ} \mathbf{C}\right)$} & \multicolumn{2}{c|}{ TSD (mg/L) } \\
\cline { 2 - 7 } & Día 1 & Día 7 & Día 1 & Día 7 & Día 1 & Día 7 \\
\hline A caroliniana & $7,80 \pm 0,00$ & $8,00 \pm 0,17$ & $26,00 \pm 0,00$ & $26,00 \pm 0,00$ & $91,00 \pm 0,00$ & $94,67 \pm 3,21$ \\
\hline L. minor & $7,80 \pm 0,00$ & $7,83 \pm 0,06$ & $26,00 \pm 0,00$ & $25,33 \pm 0,58$ & $91,00 \pm 0,00$ & $100,33 \pm 7,09$ \\
\hline S. auriculata. & $7,50 \pm 0,00$ & $7,60 \pm 0,10^{*}$ & $26,00 \pm 0,00$ & $24,00 \pm 0,00^{*}$ & $92,00 \pm 0,00$ & $122,00 \pm 1,73$ \\
\hline P. stratiotres. & $7,50 \pm 0,00$ & $7,60 \pm 0,00$ & $26,00 \pm 0,00$ & $24,00 \pm 0,00^{*}$ & $92,00 \pm 0,00$ & $122,67 \pm 2,31$ \\
\hline C. thalictroides & $7,50 \pm 0,00$ & $7,73 \pm 0,06$ & $26,00 \pm 0,00$ & $24,00 \pm 0,00^{*}$ & $90,00 \pm 0,00$ & $131,00 \pm 13,00$ \\
\hline E. crassipes & $6,60 \pm 0,00$ & $7,07 \pm 0,64^{*}$ & $24,00 \pm 0,00$ & $24,00 \pm 0,00^{*}$ & $72,00 \pm 0,00$ & $62,00 \pm 37,03^{*}$ \\
\hline Control & $6,60 \pm 0,00$ & $8,07 \pm 0,06$ & $24,00 \pm 0,00$ & $26,33 \pm 0,58$ & $72,00 \pm 0,00$ & $108,67 \pm 5,51$ \\
\hline
\end{tabular}

* Indica que existen diferencias significativas en comparación con el control según Kruskall-Wallis $(p<0,05)$ 
Los parámetros de $\mathrm{pH}$ y temperatura a lo largo del ensayo se mantuvieron con una relativa estabilidad solo mediante el test de Kruskall-Wallis se encontró que poseen diferencias significativas. Las especies $E$. crassipes y $S$. intermedia presentaron un $\mathrm{pH}$ de $7,067 \pm 0,643$ y 7,200 $\pm 0,000$, menor al control 8,067 $\pm 0,058(H=18,99 ; p=0.008)$.

Asimismo, la temperatura del agua se redujo significativamente para la mayoría de las especies para el día 7 del ensayo. En la Tabla 1 podemos observar que $C$. thalictroides, $E$. crassipes, $P$. stratiotes y $S$. auriculata presentaron un valor de $24,00 \pm 0,00{ }^{\circ} \mathrm{C}$ significativamente menor al control $\left(26,33 \pm 0,57^{\circ} \mathrm{C}\right)$.

Se realizó una prueba estadística de Spearman Rho para evidenciar la relación entre los parámetros fisicoquímicos y la remoción de $E$. coli y coliformes totales, donde podemos apreciar en el Tabla 2, una correlación directa entre la concentración de E. coli y el pH (rs $=0,847 ; p=0.000$ ) y la temperatura ( $r s=0,944 ; p=0,000)$ lo que indica que a mayor $\mathrm{pH}$ y temperatura mayor concentración de bacterias.

Tabla 2. Análisis de correlación de Spearman entre los parámetros del bioensayo $\mathrm{pH}$, temperatura, sólidos totales disueltos (TSD), concentración de coliformes totales y E. coli.

\begin{tabular}{lccc}
$\mathrm{pH}$ & $\mathrm{TSD}$ & Temp $^{\circ} \mathrm{C}$ & E. coli \\
\hline TSD & $-0,282$ & & \\
& 0,181 & & \\
\hline Temp $^{\circ} \mathrm{C}$ & 0,778 & $-0,480$ & \\
& 0,000 & 0,018 & \\
\hline E. coli & 0,847 & $-0,455$ & 0,944 \\
& 0,000 & 0,025 & 0,000 \\
\hline Coliformes totales & 0,228 & $-0,454$ & 0,271 \\
& 0,283 & 0,026 & 0,200
\end{tabular}

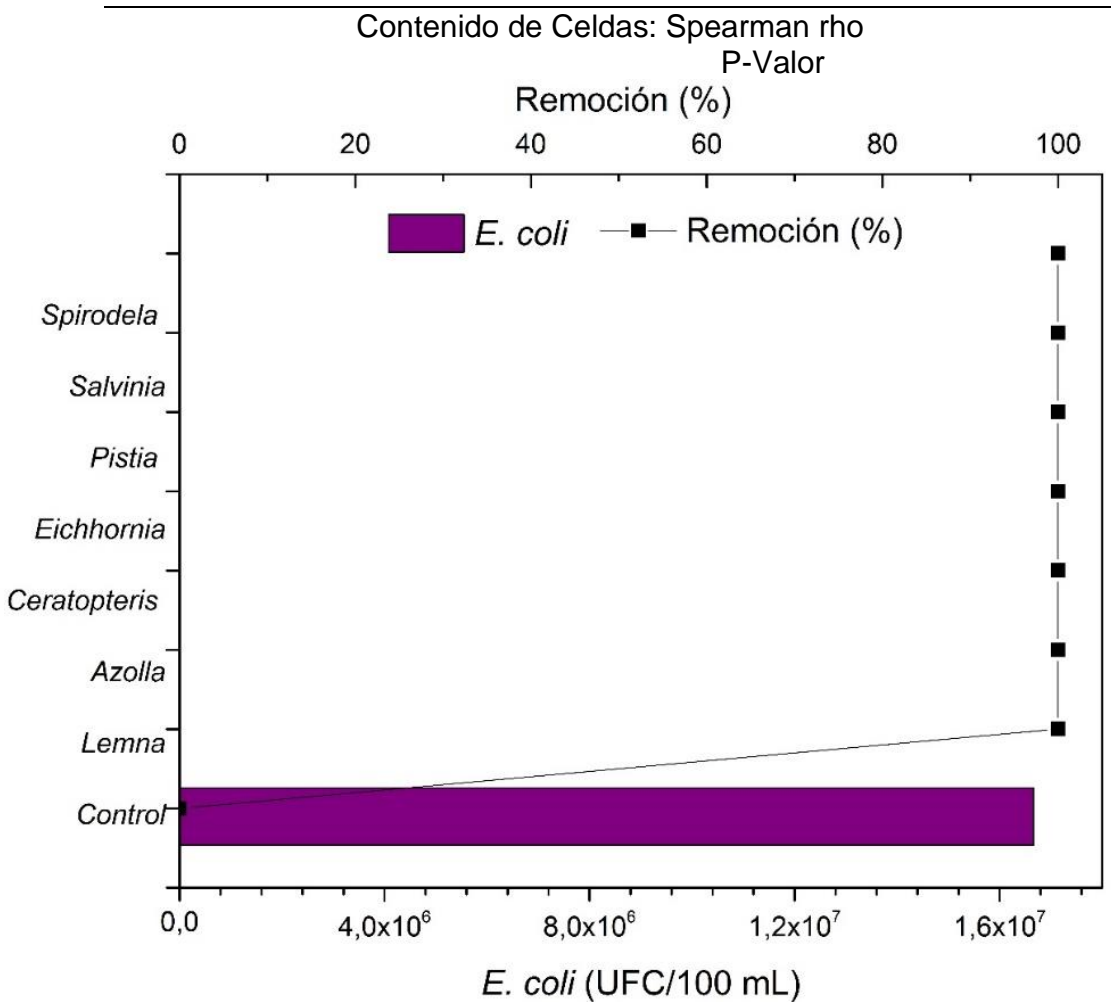

Figura 5. Efecto del bioensayo con diferentes especies de plantas sobre la concentración de $E$. coli en las aguas servidas. - Indica el porcentaje de eficiencia de cada planta en la eliminación de E. coli. 


\section{Capacidad de las plantas para remover $E$. coli y coliformes totales de aguas servidas}

Las plantas que mostraron una elevada tasa de eliminación tanto de coliformes como de $E$. coli se sometieron a un ensayo con aguas servidas para determinar la tasa de remoción. Las especies $S$. intermedia, $S$. auriculata, $P$. stratiotes, E. crassipes, $C$. thalictroides, $A$. caroliniana y L. minor alcanzaron una remoción del $99.97 \%$ de E.coli en contraste con el control que inició con un contaje de $120 \mathrm{UFC} / 100 \mathrm{ml}$ de E.coli y después de 7 días se elevó hasta $1.67 \times 10^{7}$ UFC/100 ml (Figura 5).

Así también, las plantas que mostraron una buena tasa de eliminación de coliformes totales con $100 \%$ de remoción fueron: S. auriculata y A. caroliniana en comparación al control que empezó con una población bacteriana base de $42 \times 10^{2}$ UFC/100 ml de coliformes fecales llegando hasta $5.24 \times 10^{8} \mathrm{UFC} / 100 \mathrm{ml}$ (Figura 6).

El orden de remoción fue: $S$. auriculata $=A$. caroliniana $>C$. thalictroides $>P$. stratiotes $>$ L. minor $>S$. intermedia $>$ E. crassipes.
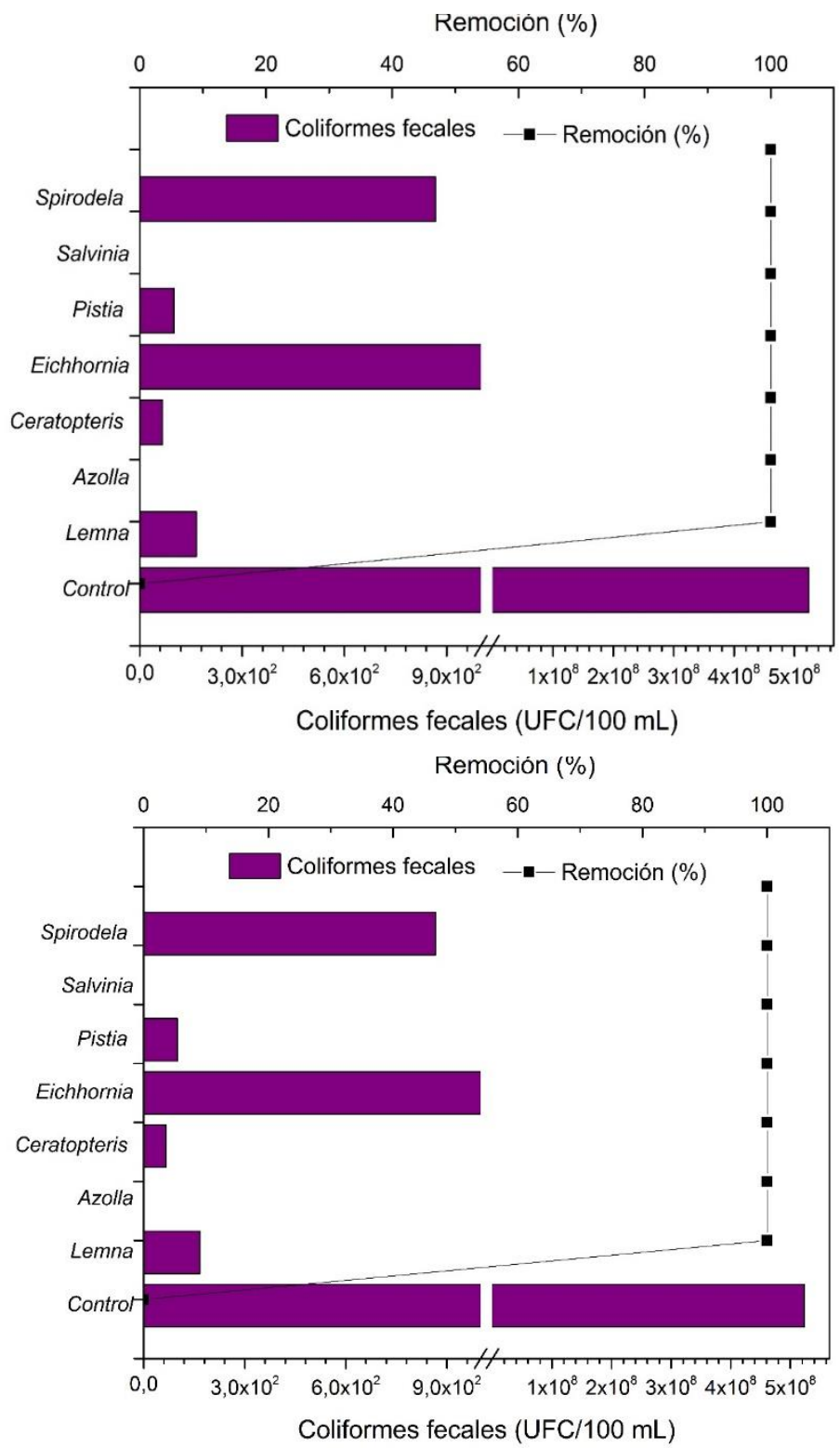

Figura 6. Efecto del bioensayo con diferentes especies de plantas sobre la concentración de coliformes totales en las aguas servidas. - Indica el porcentaje de eficiencia de cada planta en la eliminación de coliformes totales. 
En la Tabla 3 se muestra el inventario de plantas recomendadas para remoción de coliformes totales y $E$. coli en aguas servidas.

Tabla 3. Inventario de plantas acuáticas recomendadas para remover coliformes totales y E. coli de aguas servidas.

\begin{tabular}{lll} 
& \multicolumn{2}{l}{ Capacidad de remoción } \\
total (100\%)
\end{tabular}

\section{Discusión}

Se seleccionaron plantas con potencial para eliminar coliformes totales y se verificó su capacidad para eliminar E. coli ATCC 25922. De las plantas estudiadas las más eficientes fueron: $C$. thalictroides, $E$. crassipes, $P$. stratiotes, $S$. auriculata y $S$. intermedia que eliminaron un $100 \%$ a la $E$. coli, valores superiores a los hallados por Neralla y Weaver (2000) quienes utilizaron la especie Typha latifolia y encontraron una eficiencia de remoción del $42.75 \%$, sin embargo el tiempo de retención de estos autores fue menor (2 días) al empleado en el presente trabajo (7 días).

En relación con los coliformes totales las plantas acuáticas en siete días disminuyeron su concentración por debajo de los límites máximos permisibles (1000 $\mathrm{NMP} / 100 \mathrm{ml}$ ) para agua de consumo humano, uso doméstico, riego y pecuario según el Acuerdo Ministerial 097A (2015).

La única especie que no eliminó en un $100 \%$ la población de coliformes fue $E$. crassipes, registrando $6433 \mathrm{UFC} / 100 \mathrm{ml}$. Estos resultados coinciden con los hallados por Rojas (2005), quien demostró que existen bacterias asociadas a $E$. crassipes tales como E. coli, Pantoea sp., Shigella sp., Klebsiella sp., Enterobacter cloacae, Pseudomona putida y Chromobacterium violaceum. Este autor también comparó la cantidad de bacterias asociadas a las raíces de plantas acuáticas de un humedal artificial para tratamiento de aguas servidas y demostró que $E$. crassipes presenta un mayor número de UFC/100 ml y una mayor diversidad de bacterias asociadas a sus raíces que $P$. stratiotes y $A$. caroliniana (Rojas, 2005).

Además, comparando los presentes resultados con los reportados por otros autores se observa que solo dos plantas $S$. auriculata y $A$. caroliniana alcanzaron una eficiencia del $100 \%$ en la eliminación de coliformes fecales, cercano al valor registrado para Phragmites australis que alcanzó un $99.7 \%$ y $99.6 \%$ en la remoción de E. coli y coliformes fecales, respectivamente (Mantovi et al., 2003).

Los factores que podrían haber influido en la remoción de bacterias como se demostró con el análisis de correlación fueron el $\mathrm{pH}$, la temperatura, y la sedimentación. Según Solic y Krstuloviic (1992) el pH óptimo para la E. coli es de 6 - 7 y valores superiores provocan un declive en su población. Asimismo, Mayo (2004) apoya la teoría que a pH alcalinos mueren las coliformes fecales. En el experimento el $\mathrm{pH}$ en los controles sin las plantas se redujo de 8.20 a 7.40 , por el contrario, en los tratamientos con las plantas el pH aumentó hasta 8.45 lo que podría haber promovido la muerte de las bacterias. Las especies que aumentaron el $\mathrm{pH}$ a 8.45 fueron $A$. caroliniana, $y S$. auriculata lo que explicaría su eficacia en la remoción de bacterias.

También hubo una reducción de la temperatura de $2-3^{\circ} \mathrm{C}$ lo que también pudo haber influido en la muerte de las bacterias; ya que la temperatura óptima para el 
crecimiento de las coliformes es de $37-40^{\circ} \mathrm{C}$ por lo que la reducción a $24{ }^{\circ} \mathrm{C}$ puede haber influido en su eliminación (Mayo, 2004).

También, la sedimentación pudo haber sido otro mecanismo de eliminación de bacterias, ya que las plantas podrían incidir en el incremento en la tasa de precipitación de sólidos suspendidos y disueltos en aguas servidas. En el ensayo de Zimmels et al. (2006) y en el presente trabajo se observó un aumento en la concentración de sólidos totales disueltos (TSD) al cuarto día del bioensayo, con una posterior disminución por precipitación. Además, se observó una correlación entre el TSD y la concentración de bacterias. En el estudio se apreció precipitación de material en suspensión y disuelto al cual podrían haberse unido las bacterias gram negativas por presentar una membrana externa compuesta por fosfolípidos y lipopolisacáridos que les confiere una carga electrostática negativa total a la pared celular (Buckley, Bender, Stahl, Martinko, y Madigan, 2015), por lo que podrían unirse a iones positivos de los sólidos disueltos y del material en suspensión.

El mecanismo de adsorción también pudo haber intervenido en la disminución de la concentración de coliformes. En este mecanismo las bacterias se unen a las raíces y actúan como un filtro natural. Se ha reportado que un gran número de coliformes se adhiere al cuerpo radicular de las macrófitas contribuyendo así a la eliminación de los coliformes y otros patógenos (Solano et al., 2004).

También se ha descrito que los exudados bactericidas generados por las raíces de las plantas aparte de ser tóxicos para las bacterias, pueden alterar el ambiente físico químico de la rizófora haciendo que esta sea inhabitable para futuras colonizaciones de bacterias patógenas (Akça et al., 2012). En este sentido se ha demostrado el efecto bactericida de extractos metanólicos y etanólicos de $A$. caroliniana contra las bacterias Enterococcus sp., Enterobacter aerogenes, E. coli y Pseudomonas aeruginosa (Nayak et al. 2015). Y en el caso de $S$. auriculata demostró actividad antibacterial contra $E$. coli, $P$. aeruginosa y $S$. aureus (Devi et al. 2015). Sin embargo, no se realizaron los ensayos para demostrar esta hipótesis, por lo que se propone para futuros trabajos analizar las bacteriocinas secretadas al agua por las plantas y su actividad antibiótica.

Además de la capacidad de eliminar coliformes totales y E. coli, los helechos acuáticos $S$. auriculata y $A$. caroliniana son capaces de acumular metales pesados y eliminar nitratos y fosfatos en aguas residuales según Caviedes et al. (2016) y Pernía et al. (2016), por lo que se propone el uso de estas especies para el tratamiento integral de las aguas servidas.

\section{Conclusiones y recomendaciones}

Las macrófitas $C$. thalictroides, $P$. stratiotes y $L$. minor fueron eficientes en la remoción de E. coli ATCC 25922 y coliformes totales en estudios in vitro y en aguas servidas, reduciendo la carga bacteriana por debajo de los límites máximos permisibles para agua potable y agua de uso agrícola. Las especies más eficientes fueron los helechos acuáticos $A$. caroliniana y $S$. auriculata los cuales removieron el $100 \%$ de las bacterias. Estas especies generaron variaciones sobre los parámetros fisicoquímicos que podrían estar involucrados en la eliminación de las bacterias.

Una vez analizados los resultados se acepta la hipótesis inicial de que existen plantas acuáticas capaces de eliminar coliformes totales y $E$. coli de las aguas servidas y se propone el uso de los helechos acuáticos $A$. caroliniana y $S$. auriculata para el saneamiento de aguas servidas previo a su vertido en ríos para minimizar la contaminación de los acuíferos. 


\section{Bibliografía}

Akça, L., Tunçsiper, B., y Ayaz, S. (2012). Coliform bacteria removal from septic wastewater in a pilot-scale combined constructed wetland system. Environmental Engineering and Management Journal, 11(10), 1873-1879.

APHA/AWWAWEF. (2012). Standard Methods for the Examination of Water and Wastewater. Standard Methods. 541 p.

Axelrood, P., Clarke, A., Radley, R., y Zemcov, S. (1996). Douglas-fir root-associated microorganisms with inhibitory activity towards fungal plant pathogens and human bacterial pathogens. Canadian Journal of Microbiology, 42(7), 690-700.

Bhavnani, D., De Los Ángeles Bayas, R., López, V. K., Zhang, L., Trueba, G., Foxman, B. y Eisenberg, J. N. S. (2016). Distribution of enteroinvasive and enterotoxigenic Escherichia coli across space and time in northwestern Ecuador. American Journal of Tropical Medicine and Hygiene, 94(2), 276-284. https://doi.org/10.4269/ajtmh.140337

Brix, H. (1997). Do macrophytes play a role in constructed treatment wetlands? Water Science and Technology,35(5),11-17.

Buckley, D., Bender, D., Stahl, D., Martinko, J., y Madigan, M. (2015). Brock. Biología de los microorganismos (14th ed.). Pearson.

Castrillo, M., Pernia, B., De Sousa, A., y Reyes, R. (2012). Utilization of different aspects associated with cadmium tolerance in plants to compare sensitive and bioindicator species. In: Phytotechnologies: Remediation of Environmental Contaminants. Taylor and. 2012. pp. 427-440.

Caviedes, D. I., Delgado, D. R., y Olaya, A. (2016). Remoción de metales pesados comúnmente generados por la actividad industrial, empleando macrófitas neotropicales. Producción + Limpia, 11(2), 126-149. https://doi.org/10.22507/pml.v11n2a11

Delgadillo, A.E. y González, C.A. (2011). Fitorremediación: una alternativa para eliminar la Contaminación. Tropical and Subtropical Agroecosystems. 14, 597-612.

Devi, S., Rukmini, K., Himabindu, N., \& Savithramma, N. (2015). Research Article Antibacterial Activity and Phytochemical Screening of. Int. J. Pharm. Sci. Rev. Res, 30(1), 35-38.

Dirección Nacional de Vigilancia Epidemiológica. (2017). Anuario epidemiológico 19942016.

Recuperado https://public.tableau.com/profile/vvicentee80\#!/vizhome/ETAS-2014/ANUARIO

Gerhardt, K., Gerwing, P., y Greenberg, B. (2017). Opinion: Taking phytoremediation from proven technology to accepted practice. Plant Science, 256, 170-185.

Gram, C. (1884). The differential staining of Schizomycetes in tissue sections and in dried preparations. Fortschitte Der Medicin, 2, 185-189.

Green, M., Griffin, P., Seabridge, J., Dhobie, D. (1997). Removal of bacteria in subsurface flow wetlands. Water Science and Technology, 35(5),109-116.

Levy, K., Nelson, K. L., Hubbard, A., y Eisenberg, J. N. S. (2012). Rethinking indicators of microbial drinking water quality for health studies in tropical developing countries: Case study in northern coastal Ecuador. American Journal of Tropical Medicine and Hygiene, 86(3), 499-507. https://doi.org/10.4269/ajtmh.2012.11-0263

Mantovi, P., Marmiroli, M., Maestri, E., Tagliavini, S., Piccinini, S., y Marmiroli, N. (2003). Application of a horizontal subsurface flow constructed wetland on treatment of dairy parlor wastewater. Bioresource Technology, 88(2), 85-94. https://doi.org/10.1016/S0960-8524(02)00291-2

Mayo, A. W. (2004). Kinetics of bacterial mortality in granular bed wetlands. Physics and Chemistry of the Earth, 29(15-18), 1259-1264. https://doi.org/10.1016/j.pce.2004.09.030

Montoya, H.H. (2008). Microbiología básica para el área de la salud y afines. (Segunda). Antioquia: Universidad de Antioquia. 
Nayak, N., Padhy, R. N., \& Singh, P. K. (2015). Evaluation of Antibacterial and Antioxidant Efficacy of the Fern Azolla caroliniana Symbiotic with the Cyanobacterium Anabaena azollae. Proceedings of the National Academy of Sciences India Section B - Biological Sciences, 85(2), 555-569. https://doi.org/10.1007/s40011-014-0370-3

Neralla, S., y Weaver, R. (2000). Phytoremediation of domestic wastewater for reducing populations of Escherichia Coli and MS-2 coliphage. Environmental Technology, 21(6), 691-698. https://doi.org/10.1080/09593330.2000.9618954

OMS. (2015). Informe de la OMS señala que los niños menores de 5 años representan casi un tercio de las muertes por enfermedades de transmisión alimentaria. Retrieved October 30, 2018, from http://www.who.int/es/news-room/detail/03-12-2015-who-sfirst-ever-global-estimates-of-foodborne-diseases-find-children-under-5-account-foralmost-one-third-of-deaths

Pernía, B., Mero, M., Muñoz, J., Bravo, K., Morán, N., Zambrano, J., y Torres, G. (2016). Plantas acuáticas con potencial para fitoextracción de Cadmio en arrozales del cantón Daule, provincia del Guayas, Ecuador. Ciencias Naturales Y Ambientales, 10(2), 37-51.

Rao, G., Eisenberg, J. N. S., Kleinbaum, D. G., Cevallos, W., Trueba, G., y Levy, K. (2015). Spatial variability of Escherichia coli in rivers of northern coastal Ecuador. Water (Switzerland), 7(2), 818-832. https://doi.org/10.3390/w7020818

Robinson, R. (2015). Caracterización de la calidad del agua para consumo doméstico del río Quevedo en el cantón Quevedo, provincia de Los Ríos. Tesis de Ingeniería Ambiental. Facultad de Ciencias Naturales, Universidad de Guayaquil.

Rojas, J. (2005). Diversidad bacteriana en el perifiton de raíces de Eichhornia sp, Pistia sp. y Azolla sp. Tesis de Ingeniería en Biotecnología. Instituto Tecnológico de Costa Rica.

Rojas-Higuera, N., Sánchez-Garibello A, Matiz-Villamil A, Salcedo-Reyes JC, CarrascalCamacho AK, y Pedroza-Rodríguez, A.M. (2010). Evaluación de tres métodos para la inactivación de coliformes y Escherichia coli presentes en agua residual doméstica, empleada para riego. Univ Sci. 15(2),139-149.

Solano, M. L., Soriano, P., y Ciria, M. P. (2004). Constructed Wetlands as a Sustainable Solution for Wastewater Treatment in Small Villages. Biosystems Engineering, 87(1), 109-118. https://doi.org/10.1016/j.biosystemseng.2003.10.005

Solic, M., y Krstuloviic, N. (1992). Separate and combined effects of solar radiation, temperature, salinity, and $\mathrm{pH}$ on the survival of faecal coliforms in seawater. Marine Pollution Bulletin, 24(8), 411-416. https://doi.org/10.1016/0025-326X(92)90503-X

Universidad Agraria del Ecuador. (2009). Proyecto Biomonitoreo de la calidad del agua para determinar la naturaleza y grado de la contaminación por la agricultura y actividades afines en los principales ríos en la cuenca del río Guayas. Guayaquil. Obtenido http://www.uagraria.edu.ec/documentos/investigacion/UAE_Biomonitoreo_informe_ 2_dic_2009.pdf

Valencia, R. (2018). Distribución espacial y temporal de coliformes totales y fecales en el río Yaguachi. Tesis de Ingeniería Ambiental. Facultad de Ciencias Naturales, Universidad de Guayaquil.

Valderrama, L. T., Campos, C., Velandia, S., \& Zapata, N. (1987). Evaluación del efecto del tratamiento con plantas acuáticas (E. crassipes, Lemna sp. y L. Laevigatum) en la remocion de indicadores de contaminación fecal en aguas residuales domésticas. Seminario Internacional sobre Métodos Naturales para el Tratamiento de Aguas Residuales, 193-201.

Verma, R. y Suthar, S. (2015). Lead and cadmium removal from water using duckweed Lemna gibba L.: Impact of $\mathrm{pH}$ and initial metal load. Alexandria Engineering Journal.,54(4),1297-1304.

Vizcaíno, L., y Fuentes, N. (2016). Efectos de Eisenia foetida y Eichhornia crassipes en la remoción de materia orgánica, nutrientes y coliformes en efluentes domésticos. Rev. U.D.C.A. Actual Divulg. Cient. 19, 189-198. 
Wafaa, A.E., Ismail, G., Farid, A.E., Tarek, T., y Hammad, D. (2007). Assessment of the Efficiency of Duckweed (Lemna gibba) in Wastewater Treatment. Int J Agriculure Biol., 9(5), 681-687.

Wang, Y., Ho, S., Cheng, C., Guo, W., Nagarajan, D., y Chang, J. (2016). (2016)Perspectives on the feasibility of using microalgae for industrial wastewater treatment. Bioresource Technology, 222, 485-497.

Wu, S., Carvalho, P., Müller, J., Manoj, V., Dong, R. (2016).Sanitation in constructed wetlands: A review on the removal of human pathogens and fecal indicators. Science of the Total Environment. 541, 8-22.

Zimmels, Y., Kirzhner, F., y Malkovskaja, A. (2006). Application of Eichhornia crassipes and Pistia stratiotes for treatment of urban sewage in Israel. Journal of Environmental Management, 81(4), 420-428. https://doi.org/10.1016/j.jenvman.2005.11.014 